\title{
Sensitivity Analysis of the Factors Affecting Rockfall Distance
}

\author{
Ying Yuan ${ }^{1}$, Shuaiwei Wang², Shanshan Liu² \\ ${ }^{1}$ School of Prospecting Technology and Engineering of Shijiazhuang University of Economics, \\ Shijiazhuang 050031 \\ ${ }^{2}$ Graduate School of Shijiazhuang University of Economics, Shijiazhuang 050031 \\ 1yuanyingson@163.com \\ 2626792005@qq.com \\ 31270168083@qq.com
}

Key words: Rockfall distance, orthogonal test, Univariate factor test, Rock fall, Factors

Abstract. In rock slope engineering, the research on the distance of the rockfall has a great significance for the protection of people's life and property safety. First of all, the sensitivity analysis for the factors influencing the distance of the rockfall is performed by the method of orthogonal test method. Secondly, using the univariate test method, the change law for the distance affected by the above factors is analyzed based on the Rockfall Simulation software, which is validated by the results obtained from the orthogonal test table. Finally, taking a rock fall in a collapse zone as an example, some suggestions are given according to test data results, which can provide the basis for the slope prevention and reasonable layout and optimization design for the block engineering.

\section{Introduction}

From the middle of the last century, experts and scholars at home and abroad thave carried out a lot of researches ${ }^{[1] \sim[6]}$ on the movement characteristics of the rockfall. Some simplified models are used when calculating the rockfall trajectory and judging the rockfall jumping height and rockfall distance. The actual rock movement is very complicated, and some issues are still unresolved. For example, the simplified calculation conditions ignore the shape and rotation of the rockfall, small stones are used in field tests, and the related important parameters affecting the rockfall distance still needed further research.

Aiming at the prevention of slope and the design of retaining structures, the numerical simulation software of Rockfall was used to study the motion trajectory of the rockfall; the orthogonal test method was used to perform sensitivity analysis of the influence factors. Finally, based on the testing method of single variable, the factors affecting rockfall distance was analyzed, and by comparing with the orthogonal test results, change rules of various factors in relation to rockfall distance were gotten, which provided the basis for the slope prevention and reasonable layout and optimization design of the block engineering.

\section{Sensitivity Analyses of Factors Affecting Rockfall Distance}

Based on the Rockfall software for rock slope, the numerical simulation is performed for a two dimensional rock slope example, in which three factors, i.e. slope angle, restitution coefficient and velocity of rock influencing the rockfall distance were selected and the orthogonal test was carried out by taking the rockfall distance as target, which will provide the basis for future establishing the 
prediction system of rockfall distance.

Analysis of Orthogonal Test. Orthogonal test method is a method to reduce the number of experiment as much as possible to study the multi-factor and multi-level problems while not affecting the test results. The main tool of the orthogonal test is the orthogonal table ${ }^{[7]}$. According to the principle of orthogonal test, firstly list factors affecting the rockfall distance and analyze, then carry out test by 3 factors and 3 levels using the orthogonal table, we can get 9 groups of tests, as shown in table 1. I, II, III respectively stand for the sum of rockfall distance of each factor at the same level; $\mathrm{K}$ and $\mathrm{R}$ are the corresponding averages and ranges for column I, II, III, respectively. In order to obtain the sensitivity of each factor affecting the results, variance analysis is performed for orthogonal test results in table 1 , as shown in table 2.

Table 1 Orthogonal test

\begin{tabular}{|c|c|c|c|c|}
\hline Factor & Angle $\left(^{\circ}\right)$ & Restitution coefficient $\left(\mathrm{R}_{\mathrm{n}} / \mathrm{R}_{\mathrm{t}}\right)$ & Velocity $(\mathrm{m} / \mathrm{s})$ & Distance $(\mathrm{m})$ \\
\hline Test 1 & 30 & $0.3 / 0.8$ & 0.1 & 75.005 \\
\hline Test 2 & 30 & $0.35 / 0.85$ & 0.5 & 75.869 \\
\hline Test 3 & 30 & $0.4 / 0.9$ & 1 & 75.916 \\
\hline Test 4 & 40 & $0.3 / 0.8$ & 0.5 & 76.16 \\
\hline Test 5 & 40 & $0.35 / 0.85$ & 1 & 75.84 \\
\hline Test 6 & 40 & $0.4 / 0.9$ & 1 & 75.96 \\
\hline Test 7 & 50 & $0.3 / 0.8$ & 0.1 & 74.96 \\
\hline Test 8 & 50 & $0.35 / 0.85$ & 0.5 & 74.24 \\
\hline Test 9 & 50 & $0.4 / 0.9$ & 224.445 & \\
\hline I & 226.818 & 227.625 & 226.296 & \\
\hline II & 227.961 & 225.216 & 226.716 & \\
\hline III & 222.681 & 224.616 & 225.819 & \\
\hline K & 225.82 & 225.819 & 1.851 & \\
\hline R & 5.28 & 3.009 & & \\
\hline
\end{tabular}

Table 2 Variance analysis

\begin{tabular}{|c|c|c|c|c|c|}
\hline Factor & $\begin{array}{c}\text { Sum of square } \\
\text { deviations }\end{array}$ & $\begin{array}{c}\text { Contribution rate } \\
\mathrm{P}\end{array}$ & $\begin{array}{c}\text { Degree of } \\
\text { freedom }\end{array}$ & Ratio of F & critical value of F \\
\hline Angle $\left(^{\circ}\right)$ & 15.43 & 0.60 & 2 & 3.011 & 4.46 \\
\hline $\begin{array}{c}\text { Restitution } \\
\text { coefficient(Rn/Rt) }\end{array}$ & 5.07 & 0.20 & 2 & 0.567 & 4.46 \\
\hline Velocity & 2.92 & 0.12 & 2 & 0.141 & 4.46 \\
\hline Error & 2.17 & 0.08 & 2 & & \\
\hline
\end{tabular}

It can be seen from Tables 1 and 2, when different levels of each factor are taken and the value of $\mathrm{K}$ are identical, the test data combinations for the three factors and three levels are orthogonal; the results of each factor on the rockfall distance directly obtained from range $\mathrm{R}\left(\mathrm{R}_{\text {Angle }}>\mathrm{R}_{\text {Restitution }}\right.$ coefficient $>R_{\text {Velocity }}$ ) is the same as that obtained from the deviation square and ratio of $F$ $\left(F_{\text {Angle }}>F_{\text {Restitution coefficient }}>F_{\text {Velocity }}\right.$ ), that is to say, the sensitivity order is slope angle, restitution coefficient, followed by the final velocity. So the minimum combination of rockfall distance can be obtained, the slope angle taking 30 degrees, the Restitution coefficient $0.35-0.85$ and the velocity 1 $\mathrm{m} / \mathrm{s}$, which can provide the most scientific security scheme for the design of artificial slope parameters. At the same time, it can be seen from the contribution rate of $\mathrm{P}$ for each factor that the slope angle is far greater than the restitution coefficient, and the restitution coefficient is far greater than the velocity; the error term shows that other factors are neglected, needed further study.

Influencing Factors. Taking a single slope, with slope angle of $45^{\circ}$ and restitution coefficient of $0.35-0.85$, as an example, use univariate factor test and design a single variable test within the scope of slope control taken by the orthogonal test. Appropriately expand the range of the slope 
angle to analyze the change rules of different factors affecting the rockfall distance, draw univariate test curves, as shown in Fig. 2 to Fig. 4, and compare to the results in Fig. 1 obtained by the orthogonal test.

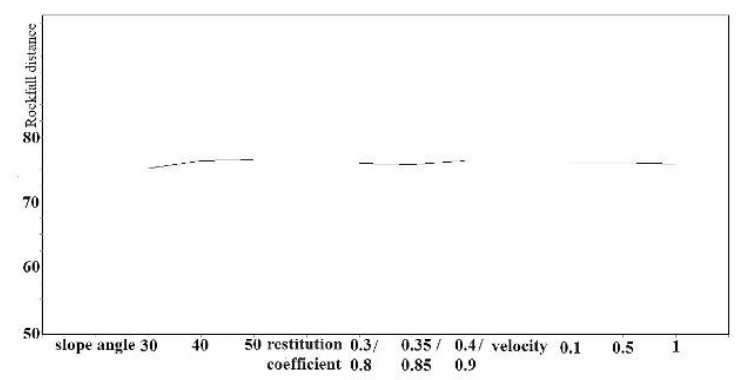

Fig 1 Curve by orthogonal table

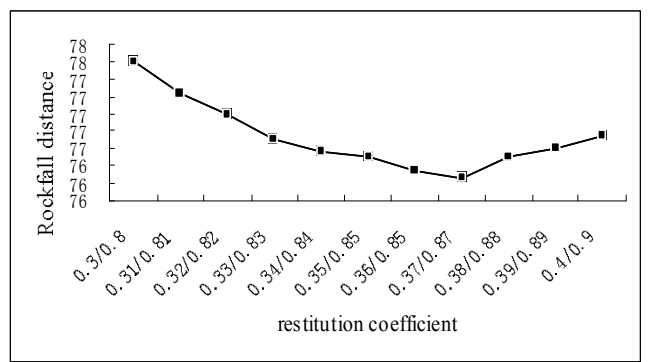

Fig.3 Rockfall distance with relation to the restitution coefficient

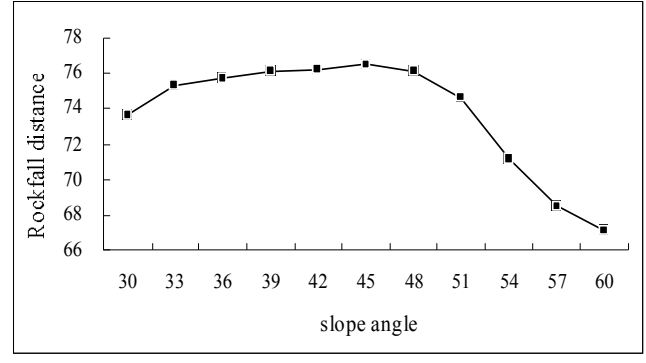

Fig.2 Rockfall distance with relation to the slope angle

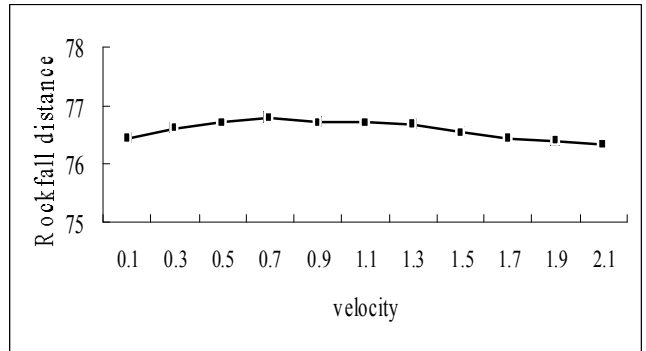

Fig.4 Rockfall distance with relation to the velocity

It can be seen from Fig. 1 to Fig. 4 that the curve of rockfall distance grows slightly with the slope angle when ranging in $30^{\circ} \sim 50^{\circ}$ and has a overall convex trend, close to the curve by the orthogonal test; when the slope angle ranges in $50^{\circ} \sim 60^{\circ}$, the curve of the rockfall distance is a decreasing function, close to the curves by field test which are also consistent with those of previous studies ${ }^{[1]}$. However, it can be seen that the curve of rockfall distance with the restitution coefficient is contrary to the result of the slope angle; when the restitution coefficient changes from the initial value of $0.3-0.8$ to the value of $0.37-0.87$, the curve shows a decreasing trend, then the rockfall distance increases with the growth of the restitution coefficient, and has a overall concave trend, close to the curves by the orthogonal test. Additionally, it can be seen that the effect of velocity change on rockfall distance is the smallest, the rockfall distance falling between $76.3 \mathrm{~m}$ and $76.8 \mathrm{~m}$; rockfall distance with the velocity is similar to the slope.

\section{Illustrative example of a rockfall}

Larger dangerous rockfall on a high rock slope occurred in a disaster area. According to reconnaissance and engineering survey, the main direction in the collapse zone is 263 degrees, exactly facing the center of residential area of the villagers, threatening the villages and houses. Unstable rocks fall down subjected to the slope terrain. To simulate the characteristics of these rockfalls, simplify the whole slope into two sections, then draw slope shape with AUTOCAD as shown in Fig. 5 and is imported into Rockfall software, and finally set the parameters. According to the field survey and the long-term observation, unstable rock with $5 \mathrm{~kg}$ weight and the initial horizontal velocity of $1 \mathrm{~m} / \mathrm{s}$ is taken for calculation and analysis. The simulated trajectory of the unstable rock is shown in Fig. 6, and the rockfall distance shown in Fig. 7, the jumping height in Fig. 8 and the total kinetic energy in Fig. 9 


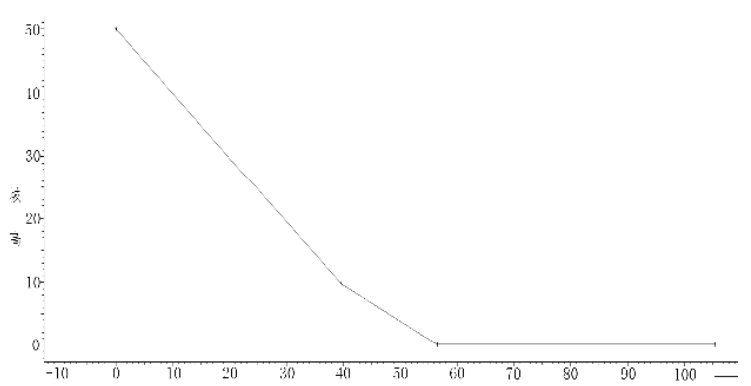

Fig. 5 The Slope Shape

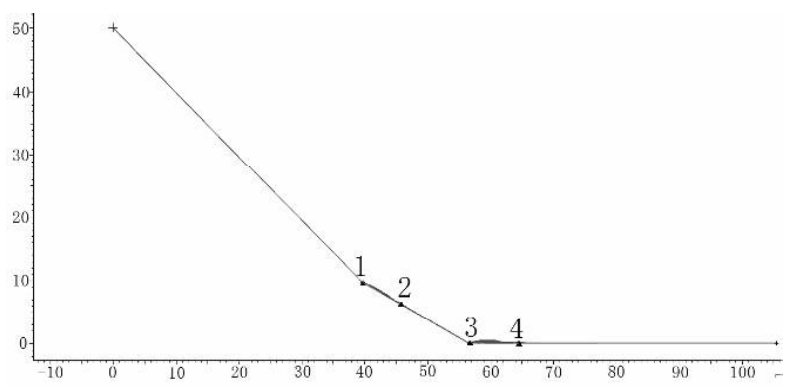

Fig. 6 Rockfall Trajectory Simulation

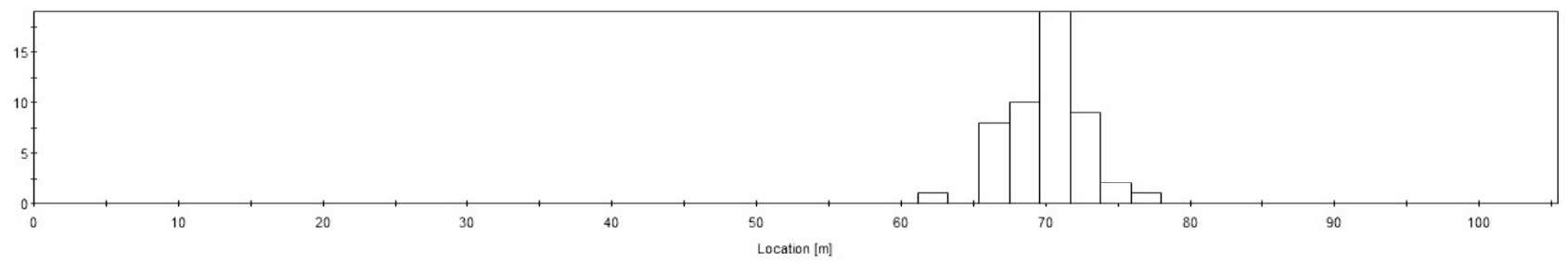

Fig. 7 Rockfall Distance [m]

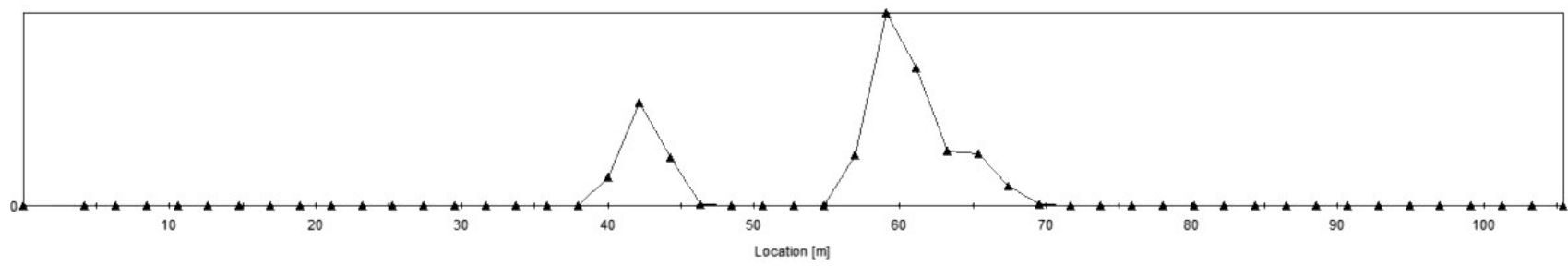

Fig. 8 Jumping Height [m]

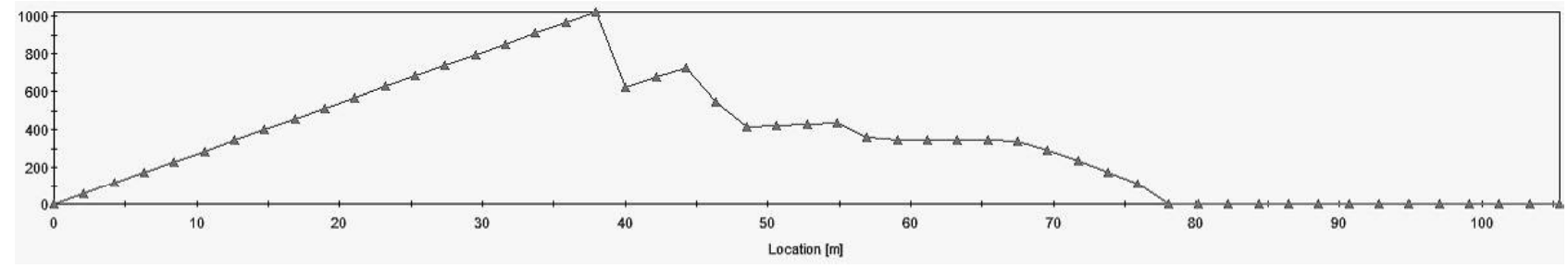

Fig. 9 Total kinetic energy $[\mathrm{J}]$

It can be seen from Fig. 6 to Fig. 9 that from the starting position, the motion of rockfall accelerates and energy increases, and when slope shape changing, rockfall bounces, with energy loss and energy conversion in the whole process of rockfall motion. According to the results of orthogonal test and univariate test above, the slope control should be designed in the sensitivity range of factors affecting rockfall distance smaller. For example, the probability distribution of rockfall distance was concentrated at $70 \mathrm{~m}$ in the case of the original slope, while combined with the optimal rockfall distance and revising the slope parameters of the restitution coefficient and the velocity, the probability distribution of rockfall distance was concentrated at $55.88 \mathrm{~m}$, reduced by $14.12 \mathrm{~m}$, about $20 \%$. Therefore, in the design of slope control, based on the actual terrain, the slope can be treated by cutting on the top to change the initial state of motion of rockfall and increasing vegetation on the slope to change the restitution coefficient of the slope; then according to the jumping height of the rockfall, build retaining wall at the steep junction where is flat at the foot of the slope in the collapse zone, reducing the rockfall velocity and impact energy and blocking the unstable rock and rockfall on the slope. 


\section{Conclusions}

Based on the Rockfall software, the effects of factors on rockfall distance were analyzed by using numerical simulation method and with the help of orthogonal test and univariate Factor and the following conclusions are drawn,

1) During analyzing the change rules of factors affecting rockfall distance, the number of orthogonal test was far less than that of univariate test, and the test results of both methods coincided.

2) The sensitivity orders of the factors affecting rockfall distance were that the slope angle was the maximum, followed by the restitution coefficient and then the velocity. The effects of restitution coefficient and velocity on rockfall distance were much smaller compared with slope angle.

3) According to the results of rockfall distance curves of different factors, the sensitive areas and the optimal falling distance subjected to the effects of the slope angle, the restitution coefficient and the velocity can be determined, which can provide the basis for the design of slope control.

\section{Reference}

[1] HU Hou-tian. Collapse and Rockfall [M]. Beijing: China Railway Publishing House, 1989.

[2] Chen Hong-kai. The Principle of Dangerous Rock Prevention and Cure [M]. Seismological press, 2006

[3] Ritchie A M. Evaluation of rockfall and its control [J].High way Research Record. 1963,17:13-18

[4] Azzoni, A, Barbera, G. L., Zaninetti, A. Analysis and Prediction of Rockfalls Using a Mathematical Model [J].1995, 32(07):709-724.

[5] SPANG RM. Rockfall barriers design and practice in Europe [C]/Proc. one day seminar on planning, design and Implementation of debris flow and rockfall hazards mitigation measures. Hong Kong, 1998, 91-98.

[6] Chen Hong-kai, Xian Xue-fu. Stability Analysis Method for Perilous Rock [J]. Chinese Journal of Applied Mechanics, 2009, 26(2): 278-282+406-407.

[7] Wang Wan-zhong. Design and analysis of experiments [M]. East China Normal University press, 1997 